\title{
The Relationship Between Social-Emotional Difficulties and Underachievement of Gifted Students
}

\author{
Sabrina Blaas \\ The University of Queensland, Brisbane, Queensland, Australia
}

\begin{abstract}
Gifted students are a diverse minority group with high intelligence and talent whose needs are often unrecognised and unmet. It is believed that this group of students, from a range of backgrounds, socio-economic statuses and abilities, may experience a range of social-emotional difficulties, including peer exclusion, isolation, stress, anxiety, depression and destructive perfectionism. Literature also reveals that gifted and talented students are underachieving at school. Many educators do not recognise or meet the needs of gifted students as there is a false perception that they can look after themselves (Neihard, Reis, Robinson, \& Moon, 2002). As research indicates, there is a positive correlation between poor social-emotional development and scholastic underachievement in gifted students (Australian Council for Educational Research, 2010; Queensland Government, 2013). While this may be true, there is limited understanding of how these variables influence one another. Many researchers believe that social-emotional difficulties cause school underachievement, whereas others argue that school underachievement results in social and emotional problems. Furthermore, many researchers dispute these arguments altogether, and believe that these problems are a result of external factors, including family, school, and community environments. Given these contrasting viewpoints, critical investigation is necessary in order to develop a more conclusive understanding of this relationship. This article aims to critically analyse the scope of the current literature, and provides recommendations for further research, as this may result in better development of programs to further support the social-emotional and academic needs of gifted students.
\end{abstract}

Keywords: social-emotional, gifted

Current literature on the relationship between social-emotional difficulties and underachievement is believed to be fraught with gaps and inconsistencies. This may be due to a lack of consensual evidence and research on the particular topic (McCoach \& Siegle, 2003). Research reveals that social-emotional difficulties and

ADDRESS FOR CORRESPONDENCE: Sabrina Blaas, 1/96 Herries Street, East Toowoomba QLD 4350, Australia. E-mail: sabrinadianablaas@gmail.com 
underachievement of gifted students is the result of both internal and external factors; however, it is less understood as to which influences have greater effects on the other. Some researchers believe that social-emotional wellbeing has a dramatic impact upon academic performance. As a result, there is a growing awareness among education departments and policy makers on the need to improve the socialemotional wellbeing of students. However, although there is significant evidence on poor social-emotional health and its impact on education, there is less evidence on underachievement and its impact on social-emotional wellbeing, especially with gifted students.

Gifted students, namely students with a well above average intelligence, are ironically particularly vulnerable to academic underachievement (Reis \& McCoach, 2000). Education systems in Australia understand the need to better support gifted students by allocating specific funding to implement gifted and talented programs within schools (Education Queensland, 2013). However, more support is needed as gifted students are believed to continue to underachieve, increasing the chances for further negative implications, including school dropout (Renzulli \& Park, 2002). Research indicates that 'giftedness' raises the chance of school dropout; however, there are still large discrepancies between the number of gifted students who do and do not drop out of high school. A study by Robertson (1991) found that between $18-25 \%$ of gifted students drop out of high school, while Renzulli and Park (2002) found that only $5 \%$ of gifted students drop out. The differing research results may be due to inconsistencies in the definition of giftedness, the date of the study, and differing research methods. Comparing these results to the American national average of dropout, which was at $8.1 \%$ in 2011 (NCES, 2011), gifted students are at a similar to potentially much higher risk of school dropout than the national average, despite being academically able to achieve. A strong factor of underachievement, and thus school dropout, may be the result of external/internal factors, such as poor social-emotional wellbeing, rather than a lack of ability and intelligence. In order to better support gifted students, it is important to better understand the relationship between social-emotional difficulties and school underachievement. By better understanding the relationship between social-emotional difficulties and school underachievement, guidance officers and educators may be able to better support gifted student needs.

\section{Terminology}

For the purposes of this article the most accepted, relative and current definitions are used to define specific terms. 'Gifted underachievement' is defined as the 'incongruence between ability and performance' (Baum, Renzulli, \& Hebert, 1995; Rimm, 1997). When applying this term, gifted underachievement is when, for instance, a 10-year-old gifted student is performing at the level of an average 10-year-old, yet has the cognitive ability to perform at a much higher level. Therefore, gifted students who underachieve may still be performing at a similar level to his/her age level peers. However, the definition of 'underachievement' differs significantly, and is used to describe non-gifted students who are underachieving by at least one grade level in at least one subject area (Mandel \& Marcus, 1995). The definition to describe 'underachievement' is far more specific than the term 'gifted underachievement', which may result in many discrepancies when determining whether a gifted 
student is underachieving. As educators and guidance officers may be less likely to identify gifted underachievers due to the lack of benchmark, gifted students are less likely to receive the support necessary to improve their performance at an early stage.

Another discrepancy that often results in a lack of consensual agreement is the term 'giftedness'. For the purposes of this article, 'giftedness' is defined as a person with potential to excel in intellectual, social, physical or creative domains (NSW Department of Education and Communities, 2011). However, many define 'giftedness' through intelligence assessment, which may not identify all gifted students, as some may be underperforming due to reasons such as poor social-emotional wellbeing. For instance, a person who is exceptionally gifted has an intelligence quotient (IQ) of 160-179, whereas a person who is profoundly gifted has an IQ of 180 or more (Neihard, Reis, Robinson, \& Moon, 2002). Yet this causes disagreements, as some argue that IQ tests are unreliable due to test and/or administration errors (Reis \& McCoach, 2000). It is evident that there are many definitions for the term 'giftedness', which may cause inconsistencies in research results.

'Social-emotional wellbeing' is another term that often results in confusion and needs clarification. It is a broad term that encompasses having an ability to display empathy, manage feelings more easily, have self-confidence, and have the ability to develop friendships more easily (Neihard et al., 2002). Therefore, when discussing 'social-emotional difficulties', this refers to a person's inability to control their feelings/thoughts, which can result in a range of negative emotions, including sadness/depression, anxiety, poor social adjustments, poor self-regulation skills, a lack of confidence, problems with organisation, and low levels of cooperation (Australian Institute of Health and Welfare, 2012). The broad definition of socialemotional wellbeing is used in this article to examine self-concept, self-perception and self-regulation and how these may impact school achievement.

\section{The Nature of Gifted Students}

In order to best examine the relationship between social-emotional difficulties and underachievement of gifted students, the specific social-emotional and school performance issues gifted students face need to be examined. This is achieved through examining the nature and characteristics of gifted students, the current issues gifted students face, and the vulnerability of this group.

Gifted students are at particular risk of underachievement and social-emotional difficulties due to the many characteristics involved with giftedness. Despite coming from a range of backgrounds and cultures, including socio-economic statuses, abilities and talents, there are certain traits that gifted students have in common. Gifted students are known to be sensitive, perfectionists, and experience social isolation, which are all considered risk factors for poor social-emotional difficulties and underachievement (Blatt, 1995, Dixon \& Scheckel, 1996; Jackson, 1998). Furthermore, gifted students are believed to be at risk of both internalising and externalising problems, including depression, anxiety, anger/frustration, irritability, failure-avoidance behaviour, and low self-esteem (Reis, Neu, \& McGuire, 1995; Rimm, 1995). These internalising and externalising problems, such as negative perfectionism and failure-avoidance, directly contribute to both poor socialemotional adjustments and underachievement (McRae, 2002; Moon \& Hall, 1998). 
From these findings, significant research indicates that gifted students are at a risk of poor social-emotional wellbeing and underachievement. One article, however, reveals that gifted students are at no increased risk of underachievement and social-emotional difficulties than any other students (Heller, Monks, Sternberg, \& Subotnik, 2000). As a result, further investigation is needed to better understand the risk factors faced by gifted students.

\section{The Causes of Underachievement}

It is essential to better support underachieving students, as there are many personal and societal issues attached to underachievement. While there are significant inconsistencies between the number of gifted students who underachieve, all studies conclude that a high percentage of underachievement occurs. For instance, a study by VanTassel-Baska (2000) found that $63 \%$ of gifted students are underperforming. These problems are believed to have great impacts upon the individual and society, as underachievement occurs well after high school. Further studies in Australia are required to determine dropout rates of gifted students. It is unknown whether underachievement is a direct cause of this; however, it is important for educators, guidance officers and support staff to better support underachieving gifted students as this may minimise dropout rates and thus provide a better contribution to society and the workplace.

A large contributor to underachievement is a person's social-emotional health. Research indicates that there is a strong relationship between social-emotional development and school performance. For example, issues such as low self-image, low self-confidence and low self-efficacy result in gifted underachievement (Neihard et al., 2002; Rimm, 1995; Schunk, 1998). Furthermore, there are many socialemotional issues, such as negative attitudes and low self-motivation, which are typically found in low performing gifted students (Rimm, 1995). However, further research is crucial to understand whether poor social-emotional wellbeing, such as low self-motivation or negative attitudes, are a cause or effect of underachievement.

One cause of underachievement is poor academic self-concept. Academic selfconcept refers to the attitudes an individual has about their abilities and skills toward learning. Studies have indicated that students with low academic self-concept are likely to be low achievers, whereas students with high academic self-concept are likely to be high achievers (Diaz, 1998; Ford, 1996; Marsh, Chessor, Craven, \& Roche, 1995; Rimm, 1995; Schunk, 1998; Valentine, Dubois, \& Cooper, 2004). Research has revealed that academic self-concept and school achievement have an influence on each other; however, further research is needed to confirm whether self-concept causes underachievement or whether underachievement results in poor self-concept. There is insufficient evidence, particularly in Australia, that critically examines poor self-concept and whether it may be a cause or effect of underachievement. Through better understanding the relationship between the two variables, programs to improve social-emotional wellbeing and achievement levels among gifted students may be possible.

Another social-emotional difficulty, namely self-regulation, has an impact upon academic performance. Self-regulation is the ability to take control of one's own behaviour. Students with self-regulatory behaviour have confidence, diligence, 
autonomy, and are able to accept greater responsibility in their learning (Schunk \& Zimmerman, 1998). Students who have low self-regulatory skills are less likely to take responsibility in their learning process and are less likely to achieve high academic success. Furthermore, research indicates that self-regulated learners are able to possess high levels of self-efficacy, and these traits have been directly linked to high academic achievement (Corno et al., 2002; Pintrich, 2000; Pintrich \& Schunk, 2002; Schunk \& Zimmerman, 1998; Winne \& Perry, 2000). As evidence reveals, students with high self-regulatory behaviour are more likely to experience academic success and higher levels of achievement than students with low levels of self-regulation.

Academic self-perception is another factor that is believed to impact upon schooling outcomes. Academic self-perception is based upon how an individual perceives themselves toward learning. Researchers have found a strong correlation between positive self-perception results and good academic outcomes (Valentine, Dubois, \& Cooper, 2004). As there is believed to be a relationship between the two variables, it is unclear whether academic self-perception is a cause or effect of schooling outcomes, or whether a third variable impacts both academic self-perception and academic achievement. Further studies will help clarify the direction of causality between academic self-perception and school achievement.

It is evident that social-emotional wellbeing has a strong influence on the academic success of an individual. There is a strong relationship between high levels of social-emotional wellbeing and high school performance. There is also a correlation between poor social-emotional wellbeing and underachievement. Research indicates that self-concept, self-regulation, academic self-perception, and self-esteem all contribute to an individual's schooling success. As social-emotional wellbeing has a large impact on schooling outcomes, further research is required to determine the degree of impact. It is also vital to determine whether there is a reciprocal effect occurring, as this may result in an ongoing cycle of poor achievement and poor social-emotional wellbeing.

\section{Causes of Social-Emotional Difficulties}

There are many factors which are believed to contribute to poor social-emotional development. These include the school, home, and community environment as well as biological factors (Cauce et al., 2000; Forness \& Kavale, 2001). Individuals in a poor home environment may experience poverty, abuse, neglect and/or parental stress, which are considered to directly impact upon one's social-emotional wellbeing. However, the cause of poor social-emotional wellbeing is not always due to environmental factors. Some people may also be genetically prone to poor socialemotional adjustments and may experience depression, anxiety and negative emotions more than others (Levinson, 2006). Therefore, for some, it is a matter of learning social-emotional skills that will aid in academic success. Gifted students are believed to benefit from learning social-emotional skills as they may be more prone to poor social-emotional wellbeing.

Gifted underachievement, as well as poor social-emotional wellbeing, can be a result of poor home, school and community environments. Studies reveal that underachievement can result in issues occurring at school (Rimm, 1997), poor 
home/family environment (Baker, Bridger, \& Evans, 1998; Reis \& McCoach, 2000; Rimm, 1997), and community/societal problems (e.g., peer pressures, stigmas, low socio-economic status; Diaz, 1998; Ford, 1996; Reis \& McCoach, 2000). Many of these issues, including poor social-emotional wellbeing, may be intertwined with each other and result in higher rates of school underachievement and possible school failure. For instance, poor social-emotional wellbeing, such as low self-esteem, may be a result of a poor home environment (e.g., verbal abuse). This illustrates how poor home environments directly impact social-emotional wellbeing, which may then contribute to poor schooling outcomes.

Perfectionism is believed to cause a range of social-emotional difficulties. It is a trait commonly seen among gifted students (McRae, 2002; Mendaglio, 1994; Silverman, 1999). Gifted students who are perfectionists often set unrealistic goals that set them up for failure (Hess, 1994). Perfectionism is also considered a risk factor for many other health and social-emotional issues, including depression, eating disorders, obsessive-compulsive disorder, and suicide (Blatt, 1995). Furthermore, students who have perfectionist traits are more likely to burn out, causing further social-emotional difficulties. This is because burnout involves physical, mental, and emotional exhaustion, depression, emotional overreaction, and low self-esteem (McRae, 2002). This indicates that perfectionism is considered a risk factor for poor social-emotional wellbeing. It is essential to identify and educate gifted students on how to best manage perfectionism.

Other causes of poor social-emotional wellbeing in gifted students are the social pressures and negative stigmas associated with high academic achievers (ManorBullock, Look, \& Dixon, 1995; Reis \& McCoach, 2000; Rimm, Rimm-Kaufman, \& Rimm, 1999; Schroeder-Davis, 1999; Swiatek, 1998; Swiatek \& Dorr, 1998). Studies reveal that being labelled as 'gifted' results in limited social benefits (Rimm et al., 1999; Schroeder-Davis, 1999). It is believed that when labelled as 'gifted', students feel different to their peers and may have problems being accepted socially by others (Manor-Bullock, Look, \& Dixon, 1995; Rimm \& Rimm-Kaufman, 2000; Swiatek \& Dorr, 1998). These social-emotional difficulties, such as peer exclusion, loneliness, and isolation, cause students to withdraw from advanced subjects to avoid negative stigmas, and thus do not achieve their full potential (Davis \& Rimm, 1998). It is believed that negative stigmas result in poor social acceptance and can result in a student feeling lonely, depressed and worthless.

\section{Underachievement as the Cause for Poor Social-Emotional Difficulties}

Some studies reveal there is a reciprocal relationship between some social-emotional difficulties and school achievement. Researchers believe that self-concept is believed to be both a cause and effect of underachievement (Bracken, 1996; Guay, Marsh, \& Boivin, 2003; Marsh, Byrne, \& Yeung, 1999; Valentine, Dubois, \& Cooper, 2004). However, there is limited evidence on the degree of impact underachievement has on self-concept. It is believed that academic self-concept has a stronger influence over school performance (O'Mara \& Marsh, 2007). Research also reveals that there is a reciprocal relationship between school achievement and self-esteem. It is believed continuous poor performance at school may result in lowered self-esteem (Karande \& Kulkarni, 2005). However, there are limited studies confirming a reciprocal relationship between self-esteem and school achievement. It is essential to conduct 
further research on the relationship of self-esteem and underachievement, and to examine whether there is a reciprocal relationship between underachievement and poor confidence and low self-concept.

\section{Factors That Influence Both School Achievement and Social-Emotional Wellbeing}

It is evident that social-emotional difficulties are a strong indicator of underachievement. It is also evident that underachievement may have an impact upon socialemotional wellbeing. In order to better understand the many factors influencing both social-emotional difficulties and underachievement, it is important for guidance officers and educators to determine the many external influences on gifted students.

\section{Asynchrony Development}

Asynchrony development, which is a typical trait of giftedness, is known to have negative implications on school outcomes and social-emotional wellbeing. It refers to the 'out of sync' or uneven intellectual, physical, social and emotional development of a gifted student (Neihard et al., 2002). Gifted students with high asynchrony tend to be at higher risk of social-emotional difficulties as they are more likely to experience emotional and social strains. This is because students with high asynchrony are less likely to relate to age-related peers due to their advanced cognitive development (Gross, Macleod, Drummond, \& Merrick, 2001; Heller et al., 2000; Manor-Bullock et al., 1995; Rimm et al., 1999; Robinson, 1996; Schroeder-Davis, 1999; Swiatek, 1998). Students with asynchrony are believed to be more isolated and experience problems making friends, which places them at a higher risk of developing depression and committing suicide (Jackson, 1998; Neihard et al., 2002). As gifted students are less likely to relate to age-related peers, they are more likely to experience isolation and loneliness due to social stigmas, resulting in a higher risk of social-emotional difficulties.

Asynchrony development is also related to underachievement. Due to the negative stigmas associated with asynchrony development and high cognitive ability, gifted students are likely to hide their giftedness in order to develop more positive social relationships with age-related peers (Berndt, 1999; Reis \& McCoach, 2000; Swiatek, 1998). Especially during adolescence, students need social relationships for emotional security. Studies have found that students will withdraw from advanced subjects in order to feel more accepted by peers (David \& Rimm, 1998). Asynchrony development puts these minority students at further risk of poor social-emotional wellbeing and school underachievement. It is vital to target gifted students at an early age in order to prevent or better manage social-emotional issues that the individual may experience in their schooling career and later in life.

\section{Gifted Minority Students}

Research reveals that gifted minority students, including non-Western gifted students and twice-exceptional students, are at an even higher risk of school underachievement and social-emotional difficulties than non-minority gifted students. It 
is believed that minority gifted students have additional risk factors that place them at a higher risk of poor social-emotional wellbeing and academic underachievement.

One group of gifted minority students is those from a non-Western background. These gifted minority students are at very high risk of underachieving (Baldwin \& Vialle, 1999; Ford, 1995; Grantham \& Ford, 2003; Moore, 2003; Ogbu, 2003). Research indicates that there are additional factors that influence social-emotional wellbeing and school achievement for students from a non-Western background. Studies reveal that non-Western students, including African-American and Latino students, are faced with additional cultural challenges that impact academic results (Flowers, Zhang, Moore, \& Flowers, 2004; Howard, 2003; Moore, 2003, Ogbu, 2003). A study in the United States reveals that gifted Latino and AfricanAmerican students may face racial identity issues and are likely to feel excluded from their cultural circle for 'acting white' (Davis \& Rimm, 2003; Rimm, 2003). Studies indicate that cultural factors result in additional social strains, resulting in peer rejection within the individual's cultural circle, and loss of cultural identity of the individual. This reveals that there are additional risk factors that must be considered when enhancing social-emotional difficulties and underachievement of non-Western students. There are limited studies revealing the social-emotional difficulties and school issues of gifted minority students in Australia. Further research is needed to better examine gifted Indigenous students in Australia.

Another group of minority gifted students are twice-exceptional students. Twice exceptional students are gifted students who have a special need, such as a language barrier, physical disability, or reading disability. These minority gifted students are believed to be at a high risk of underachieving at school (Brody \& Mills, 1997; Reis, Neu, \& McGuire, 1995; Rizza \& Morrison, 2007). First, it may be difficult to identify a twice-exceptional student as gifted due to their unique barrier. It has also proven difficult to best accommodate the needs of twice exceptional students in a gifted and talented program (Reis \& McCoach, 2000). These additional consequences for twice exceptional students may result in further social-emotional implications and problems in schooling success.

\section{Implications/Recommendations}

It is evident that there is a strong relationship between social-emotional difficulties and school outcomes. It is believed that a student's social-emotional wellbeing plays an important role in their school success. However, further research is needed to understand how underachievement may affect social-emotional wellbeing and whether there is a reciprocal relationship between the two variables. Research also reveals that there are many internal and external factors, such as asynchrony development, that may contribute to both poor social-emotional difficulties and underachievement.

It is important to continue researching the relationship between social-emotional difficulties and underachievement. There is currently limited research on the degree of impact poor school performance has on social-emotional wellbeing. Also, further investigation may determine whether there is a reciprocal effect occurring between social-emotional wellbeing and underachievement. It is crucial to understand whether there is an ongoing cycle between poor school performance and 
social-emotional health that may cause gifted students to underachieve and possibly drop out of school. Also, given the conflicting literature, there is also a need for further research in order to determine the significance of poor self-esteem and its impact on school outcomes.

Furthermore, research indicates social-emotional difficulties are a strong indicator of an individual's school success. It is vital for educators, guidance officers and the learning support staff to provide further early intervention programs that aim to minimise the risk of poor social-emotional health. As there are many biological and personal factors contributing to poor wellbeing of gifted students, there is a need to better educate gifted students on how to effectively manage socialemotional wellbeing. In these programs, gifted students may learn the importance of self-concept and self-regulation, and practise different learning activities that aim to develop lifelong skills to improve wellbeing. It is essential to investigate the effectiveness of such a program, and research whether school outcomes improve through a social-emotional program.

There is a need to analyse the effectiveness of current programs that aim to enhance social-emotional wellbeing. Programs in Australia that aim to enhance socialemotional wellbeing in students include the You Can Do It program (Bernard, 2013) and programs such as FRIENDS, which are provided at the Pathways Health and Research Centre (Barrett, 2013). It is important to understand the short- and longterm impacts, both positive and negative, of these programs. As gifted students have a range of unique risk factors that place them at higher risk of social-emotional difficulties, it is necessary to determine whether modifications are required to existing programs or whether specific programs are needed to best support their needs.

\section{Conclusion}

Research indicates that there is a strong correlation between social-emotional wellbeing and school outcomes. It is evident that social-emotional wellbeing has a direct impact upon school outcomes. Furthermore, research also indicates that there is a reciprocal effect between the two variables. However, further research is imperative in order to determine the significance of underachievement and its impact on social-emotional development. It is also evident that underachievement is caused by many other factors, including poor home, school, and community environments.

Further research is needed in order to determine whether there is a reciprocal effect between social-emotional difficulties and underachievement. It has been established that there is a reciprocal effect between academic self-concept and underachievement; however, it is not known whether self-regulation and self-esteem have the same relationship. Further research could also analyse the degree of impact underachievement has on social-emotional wellbeing. There is also a need to analyse existing social-emotional programs to determine whether there is an improvement in educational outcomes when social-emotional wellbeing is improved. Further research is required to determine the reciprocal relationship between socialemotional wellbeing and school achievement of gifted students, as this knowledge can be applied to develop more effective programs to better support gifted students' needs. 


\section{References}

Australian Institute of Health and Welfare. (2012). Social and emotional wellbeing: Development of a Children's Headline Indicator. Canberra, Australia: Author.

Baker, J., Bridger, R., \& Evans, K. (1998). Models of underachievement among gifted preadolescents: The role of personal, family, and school factors. National Association for Gifted Children, 42(1), 5-15.

Baldwin, A.Y., \& Vialle, W. (1999). The many faces of giftedness: Lifting the masks. Belmont, CA: Wadsworth.

Barrett, P. (2013). Pathways Health and Research Centre. Retrieved from www. pathwayshrc.com.au

Baum, S.M., Renzulli, J.S., \& Hebert, T.P. (1995). Reversing underachievement: Creative productivity as a systematic intervention. Gifted Child Quarterly, 39(4), 224235.

Bernard, M.E. (2013). You can do it! Education. Retrieved from www.youcandoit. com.au

Berndt, T.J. (1999). Friends' influence on students' adjustment to school. Educational Psychologist, 34(1), 15-28.

Blatt, S.J. (1995). The destructiveness of perfectionism: Implications for the treatment of depression. American Psychologist, 50(12), 1003-1020.

Bracken, B.A. (1996). Handbook of self-concept. New York: Wiley.

Brody, E., \& Mills, C. (1997). Gifted children with learning disabilities: A review of the issues. Retrieved from http://www.ldonline.org/article/5914

Cauce, A.M., Paradise, M., Ginzler, J.A., Embry, L., Morgan, C.J., \& Lohr, Y. (2000). Gifted and talented students at risk for underachievement. The Center for Comprehensive School Reform and Improvement. Retrieved from www.centerforcsri.org

Corno, L., Cronbach, L.J., Kupermintz, H.K., Lohman, D.H., Mandinach, E.B., Porteus, A., \& Talbert, J. (2002). Remaking the concept of aptitude: Extending the legacy of Richard E. Snow. Mahweh, NJ: Erlbaum.

Davis, G.A., \& Rimm, S.B. (2003). Education of the gifted and talented. Needham Heights, MA: Allyn \& Bacon.

Diaz, E.L. (1998). Factors influencing the academic underachievement of talented students of Puerto Rican descent. Gifted Child Quarterly, 42(2), 105-122.

Dixon, D.N., \& Scheckel, J.R. (1996). Gifted adolescent suicide: The empirical base. The Journal of Secondary Gifted Education, 7(3), 386-392.

Education Queensland. (2013). Gifted education - Programs/provisions. Brisbane, Australia: Author. Retrieved from http://www.learningplace.com.au/deliver/

Flowers, L.A., Zhang, Y., Moore, J.L., \& Flowers, T.A. (2004). An exploratory phenomenological study of African American high school students in gifted education programs: Implications for teachers and school counsellors. Retrieved from www.subr.edu/coeducation/ejournal/

Ford, D.Y. (1995). Correlates of underachievement among gifted and non-gifted Black students. Storrs, CT: The National Research Center on the Gifted and Talented.

Ford, D.Y. (1996). Determinants of underachievement as perceived by gifted, above average, and average Black students. Roeper Review, 14(3), 130-136.

Forness, S.R., \& Kavale, K.A. (2001). ADHD and a return to the medical model of special education. Education and Treatment of Children, 24(3), 224247. 
Grantham, T.C., \& Ford, D.Y. (2003). Beyond self-concept and self-esteem: Racial identity and gifted African American students. The High School Journal, 87, 1829.

Gross, M., Macleod, B., Drummond, D., \& Merrick, C. (2001). Gifted students in primary schools: Differentiating the curriculum. Sydney, Australia: University of New South Wales.

Guay, F., Marsh, H.W., \& Boivin, M. (2003). Academic self-concept and achievement: Developmental perspective on their causal ordering. Journal of Educational Psychology, 95(1), 124-136.

Heller, K.A., Monks, F.J., Sternberg, R.J., \& Subotnik, R.F. (2000). International handbook on giftedness and talent (2nd ed.). London: Pergamon Press.

Hess, L. (1994). Life, liberty and the pursuit of perfection. Gifted Child Today, 17(3), 28-31.

Howard, T.C. (2003). A tug of war for our minds: African-American high school students' perception of their academic identities and college aspirations. The High School Journal, 87, 4-17.

Jackson, P.S. (1998). Bright star — black sky: A phenomenological study of depression as a window into the psyche of the gifted adolescent. Roeper Review, 20(3), 215221.

Karande, S., \& Kulkarni, M. (2005). Poor school performance. Indian Journal of Paediatrics, 72(11), 961-967.

Levinson, D.F. (2006). The genetics of depression: A review. Biological Psychiatry, 60(2), 84-92.

Mandel, H., \& Marcus, S. (1995). Could do better. New York: Wiley \& Sons.

Manor-Bullock, R., Look, C., \& Dixon, D. (1995). Is giftedness socially stigmatizing? The impact of high achievement on social interactions. Journal for the Education of the Gifted, 18(3), 319-338.

Marsh, H.W., Byrne, B.M., \& Yeung, A.S. (1999). Causal ordering of academic selfconcept and achievement: Reanalysis of a pioneering study and revised recommendations. Educational Psychologist, 34, 154-157.

Marsh, H. W., Chessor, D., Craven, R., \& Roche, L. (1995). The effects of gifted and talented programs on academic self-concept: The big fish strikes again. American Educational Research Journal, 28(2), 445-480.

McCoach, B.D., \& Siegle, D. (2003). Factors that differentiate underachieving gifted students from high-achieving gifted students. Gifted Child Quarterly, 47(2), 144154.

McRae, C. (2002). Addressing the social and emotional needs of gifted adolescents: Implications for counsellors. Alberta Counsellor, 27(1), 16-21.

Mendaglio, S. (1994). Gifted sensitivity to criticism. Gifted Child Today, 17(3), 24-25.

Moon, S.M., \& Hall, A.S. (1998). Family therapy with intellectually and creatively gifted children. Journal of Marital and Family Therapy, 24(1), 59-80.

Moore, J.L. (2003). Introduction. The High School Journal, 87, 1-3.

National Center for Education Statistics (NCES). (2011). Dropout rates. Retrieved online from www.nces.ed.gov/

Neihard, M., Reis, S., Robinson, N.M., \& Moon, S. M. (2002). The social and emotional development of gifted children: What do we know? Washington, DC: Prufrock Press, Inc. 
NSW Department of Education and Communities. (2011). What do we mean by the terms giftedness and talent? Sydney, Australia: Author. Retrieved from www.curriculumsupport.education.nsw.gov.au

O’Mara, A.J., \& Marsh, H.W. (2007). Support for a reciprocal effects model of selfconcept and academic achievement through a contrast of multidimensional and unidimensional approaches. Retrieved from www.trove.nla.gov.au/work/

Ogbu, J.U. (2003). Black American students in an affluent suburb: A study of academic disengagement. Mahwah, NJ: Lawrence Erlbaum Associates.

Pintrich, P.R. \& Schunk, D.H. (2002). Motivation in education: Theory, research, and applications. Upper Saddle River, NJ: Merrill-Prentice Hall.

Pintrich, P.R. (2000). Multiple goals, multiple pathways: The rope of goal orientation in learning and achievement. Journal of Educational Psychology, 92, 544-555.

Queensland Government. (2013). Gifted and talented education. Retrieved from http://www.education.qld.gov.au/

Reis, S.M., \& McCoach, D.B. (2000). The underachievement of gifted students: What do we know and where do we go? Gifted Child Quarterly, 44(3), 152-170.

Reis, S.M., \& McCoach, D.B. (2002). Underachievement in gifted and talented students with special needs. Exceptionality, 10(2), 113-125.

Reis, S.M., Neu, T.W., \& McGuire, J.M. (1995). Talent in two places: Case studies of high ability students with learning disabilities who have achieved. Storrs, CT: The National Research Center on the Gifted and Talented.

Renzulli, J.S., \& Park, S. (2002). Giftedness and high school dropouts: Personal, family and school-related factors. Storrs, CT: The Research Center on the Gifted and Talented.

Rimm, S.B. (1995). Why bright kids get poor grades and what you can do about it. New York: Crown Publications.

Rimm, S.B. (1997). An underachievement epidemic. Educational Leadership, 54(7), $18-22$.

Rimm, S.B. (2003). Social adjustment and peer pressures for gifted children. Retrieved from www.davidsongifted.org

Rimm, S., Rimm-Kaufman, S., \& Rimm, I. (1999). See Jane win: The Rimm report on how 1000 girls became successful women. New York: Crown Publications.

Rizza, M.G., \& Morrison, W.F. (2007). Identifying twice-exceptional students: A toolkit for success. Retrieved from http://escholarship.bc.edu/education/

Robertson, E. (1991). Neglected dropouts: The gifted and talented. Equity and Excellence, 25, 62-74.

Robinson, N.M. (1996). Counseling agendas for gifted young people: A commentary. Journal for the Education of the Gifted, 20, 128-137.

Schroeder-Davis, S.J. (1999). Brains, brawn, or beauty: Adolescent attitudes toward three superlatives. Journal of Secondary Gifted Education, 10(3), 134-147.

Schunk, D.H. (1998). Motivation and self-regulation among gifted learners. Louisville, MO: National Association of Gifted Children.

Schunk, D.H., \& Zimmerman, B.J. (1998). Self-regulated learning: From teaching to self-reflective practice. New York: Guilford Press.

Silverman, L.K. (1999). Perfectionism. Gifted Education International, 13, 216-225.

Swiatek, M.A. (1998). Helping gifted adolescents cope with social stigma. Gifted Child Today, 11(3), 42-45. 
Swiatek, M.A., \& Dorr, R.M. (1998). Revision of the social coping questionnaire: Replication and extension of previous findings. Journal of Secondary Gifted Education, 10, 252-259.

Valentine, J.C., Du Bois, D.L., \& Cooper, H. (2004). The relation between self-beliefs and academic achievement: A meta-analytic review. Educational Psychologist, 39, 111-133.

VanTassel-Baska, J. (2000). Curriculum policy development for secondary gifted programs: A prescription for reform coherence. National Association of Secondary School Principals, 84(15), 14-29.

Winne, P.H., \& Perry, N.E. (2000). Measuring self-regulated learning. In P. Pintrich, M. Boekaerts, \& M. Seidner (Eds.), Handbook of self-regulation (pp. 531-566). Orlando, FL: Academic Press. 